\title{
Post-Transplant Lymphoproliferative Diseases in an Elderly Population Who Underwent Cardiac Transplantation: Role of Physical Activity Rehabilitation Program
}

Antonello Sica ${ }^{1, \dagger}$, Caterina Sagnelli ${ }^{2, \dagger}$, Morena Fasano $^{1, \uparrow}$, Alessandro Spada $^{1}$, Giacomo Munier ${ }^{1}$, Vincenzo Famiglietti $^{1}$, Concetta Anna Dodaro ${ }^{3}$, Armando Calogero ${ }^{3}$, Massimo Ciccozzi ${ }^{5}$, Evangelista Sagnelli ${ }^{2}$, Cristiano Amarelli ${ }^{4}$, Ciro Maiello ${ }^{4}$, Beniamino Casale $^{6}$

1 Department of Precision Medicine, University of Campania Luigi Vanvitelli, Naples, Italy.

2 Department of Mental Health and Public Medicine, University of Campania Luigi Vanvitelli, Naples, Italy.

3 Department of Advanced Biomedical Sciences, University of Naples Federico II, Naples, Italy.

4 Department of Heart Surgery and Transplantations AO Dei Colli - V. Monaldi, Naples, Italy.

5 Medical Statistics and Epidemiology, Campus Bio-Medico University, Rome, Italy.

6 Department of Pneumology And Tisiology, AO Dei Colli - V. Monaldi, Naples, Italy.

\section{$\dagger$ : equal contribution to the work.}

Short title: Post-Transplant Lymphoproliferative Diseases and Other Neoplasms In Elderly Cardiac Transplantation

Corresponding author: Dr, Antonello Sica, Department of Precision Medicine, University of Campania Luigi Vanvitelli, Naples, Italy, 80131, Tel. +393332253315, Fax.+3908119573375, email: antonellosica@gmail.com

Conflict of interest: The authors have no conflicts of interest (political, personal, religious, ideological, academic, intellectual, commercial or any other) to declare in relation to this manuscript.

Competing Interests: The authors have declared no competing interests. 


\begin{abstract}
The incidence of post transplantation lymphoproliferative disorders (PTLDs) and other neoplasms in organ transplant patients is higher than in the non-transplanted population. This event is more frequent in older subjects, due, at least in part, to the immune dysfunction induced by immunosuppressants administered to prevent rejection. Alterations of the immune system mechanisms of protection against carcinogenesis appear to be the key role in the in the pathogenesis of these neoplasms.
\end{abstract}

The data of our study on the incidence of neoplasms occurred during a long-term follow-up in an elderly population after they underwent cardiac transplantation. This study gives, also evidence of the favorable effect of physical activity programs on cardiorespiratory and psychomotor function.

Keywords: physical activity; elderly population; mediastinal lymphomas; cardiac transplantation

\title{
1. Introduction
}

The incidence of cancer in organ transplant patients is higher than in the non-transplanted population [1-5]. This event is more frequent in older subjects, due, at least in part, to the immune dysfunction induced by immunosuppressants [6-8] administered to prevent rejection. These dysfunctions would not allow the elimination of mutated cells due to some alterations in the mechanisms of genetic duplication [9], and, consequently, the task of monitoring mutated cells, could be lost. In addition, immunosuppressed patients are more likely to be susceptible to some viral infections that may promote the onset of cancer, namely human immunodeficiency virus, human T-cell lymphotropic virus, EBV [10-13]. The influence of the immune system on the mechanisms of protection against carcinogenesis is proven by numerous studies performed in patients with primary or secondary immunodeficiencies [14-19]. Lymphocytes with receptor killer 
cell lectin-like receptor subfamily $\mathrm{k}$, member 1 (KLRK1) detect and eliminate transformed or malignant cells [20]. Some KLRK1 ligands such as MICB and MICA are expressed by many carcinomas (kidney, breast, lung, ovary, prostate, liver, colon) and in turn their expression is induced by oncogenic growth factors acting through their receptors such as EGFR (epidermal growth factor receptor) [21-24]. It has been shown that activation of EGFR can regulate the immunological visibility of transformed cells. Alterations to these mechanisms appear to be the key role in reducing immunological surveillance against neoplasms [25-28]. The most frequently encountered neoplasms in patients undergoing solid organ transplantation are generally post transplantation lymphoproliferative disorders (PTLDs) (Plasmocytic hyperplasia, PTLD, Polymorphic PTLD, Monomorphic PTLD-B and T/NK cell types, classical Hodgkin lymphoma PTLD) [29], Kaposi sarcoma, NHL EBV related, cervical uterine and anal neoplasms related to papilloma virus, liver tumors (related to HCV, HBV) [30-31], and non-melanoma skin cancer [3234]. After transplantation patients are very brittle both physically and psychologically [35]. The first step is a functional recovery and autonomy that is usually carried out in hospital with physiokinesi therapy and psychological support [36]. Once discharged, the patients should start a psychophysical rehabilitation program aimed to improve the functional capacity the behavioral conditions and the quality of life. The type of program is different from a patient to another. The preliminary evaluation is multidimensional and should include general clinical conditions, functional state of different organs, psychic state, physical-motor capacity (strength, flexibility, muscular coordination), cardiovascular function under stress conditions, comorbidities and social conditions [37]. Each of these points is very important for a correct adherence to a rehabilitation program [38]. Training can produce extremely important effects, as older people use a considerable proportion of their functional capacity to perform even simple everyday activities [39]. Programs include aerobic exercise to increase muscle endurance, exercises to strengthen the extensor muscles of the legs (which support the ability to walk and get up from a chair), and the upper limbs, useful for carrying 
out household chores and other activities of daily life [40]. Aerobic training can be gradually intensive for patients who have a faster recovery and a feeling of well-being after the transplant. In these cases, the physical activity should start from 30 minutes walking or cycling stationary at moderate intensity to be increased progressively [41]. Subsequently, a training program of 5 days a week should start consisting of 20 minutes of slow running in the open air three times a week and a moderate physical activity on the remaining two days of for least 20 minutes (cycling at a regular pace and carrying light weights) [42]. Our patients were evaluated by completing the Long Form International Physical Activity Questionnaire (IPAQ) at the starting point and at weeks 4, 8 and 12, 18 follow-ups [43]. The aim of this study was to assess the incidence of neoplasms in an elderly population of heart transplants patients who underwent transplantation at AO Dei Colli - V. Monaldi, Naples, Campania region, Italy.

\section{MATERIALS AND METHODS}

This is retrospective cohort analysis of 487 patients aged 2-70 years who received heart transplantation from March 1999 to July 2018 at AO Dei Colli - V. Monaldi, Naples, Campania region, Italy. After transplantation, patients were observed during a long-term follow-up to assess wither of new neoplasms will occur. EBV, HBV, HCV, LDH, all functional hematochemist indexes have been tested at a 4-month interval after transplantation and abdomen and superficial lymph node ultrasound was performed [44-47]. Obviously, neoplasms occurred before transplantation were not consider in this study. Immunosuppressant drugs used after transplantations were antithymocyte globulin (ATG), ciclosporin, everolimus, mycophenolate, prednisone, tacrolimus [48]. During the first 5 days, ATG was administered, followed by methylprednisolone associated with cyclosporine and mycophenolate or cyclosporine and everolimus or, after 2008, tacrolimus [49]. 
Three-hundred and sixty were excluded from this analysis, 180 because not elderly (aged less than 60 years), 103 patients because they had a history of previous cancer, 48 patients because they were lost during the follow up and 29 because they died within one year after heart transplantation for heart complication. Complete data were available for the remaining 127 patients. The incidence obtained was compared with those recently reported from Campania region (AIRTum data) [50]. All procedures were performed in accordance with the Helsinki declaration and all data were used for clinical investigation anonymously, according with what established in the informed consent and with the role of the ethics committee.

\section{RESULTS}

We found 84 incident cases of neoplasms: 15 lung cancers, 4 liver cancers, 2 biliary tract cancer, 4 pancreas cancer, 14 colon-rectal cancer, 20 PTLDs (3 Hodgkin lymphomas (HL), 14 (non-Hodgkin lymphoma) NHL, 3 plasmacytic hypeplasia), 10 urinary tract tumors (3 bladder, 7 kidney), 3 thyroid cancer, 5 HPV cancer related (3 utherin cervix, 2 anal cancer) 3 Kaposi' sarcoma, and 4 EBV- related head and neck (Figure 1).

The incident neoplasms occurred from 1 year to 7 years since heart transplantation and $67.31 \%$ of 127 in male, $59.69 \%$ of 127 in female. (Figure 1). Until October 2019, 95 of the 127 patients were still alive, $47 \%$ of male and $53 \%$ of female.

\section{DISCUSSION AND CONCLUSION}

In this observational retrospective study, we have highlighted how the onset of new malignancies in elderly patients undergoing cardiac transplantation has increased like it have been observed in the elderly population in the Campania of region (AIRTum 2019). The limit of our reported data is that they are most very full-bodied, but nonetheless in good agreement with the data 
in literature. A high incidence of PTLDs has been observed, and also increasing are the neoplasm related $\mathrm{EBV}$ and $\mathrm{HPV}$.

Physical activity has been very useful for the functional recovery of the patients. Having observed our patients a long follow up after heart transplantation, we have a clear perception that a correct lifestyle and systematic sporting activity are the basis for reducing the onset of cancer.

\section{Legend to the figure}

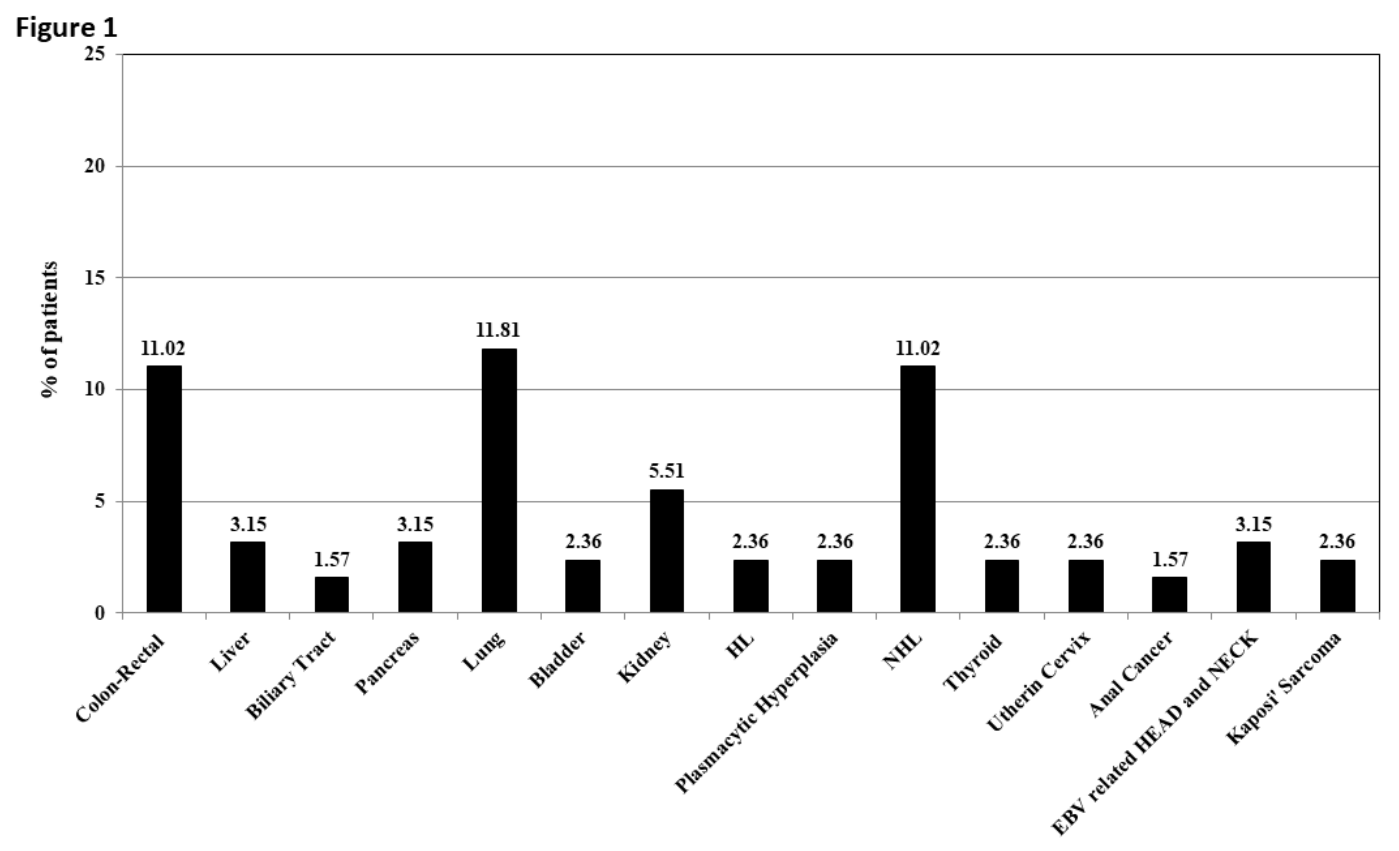

Figure 1 Type of incident cancer occurred in 84 out of 127 patients who underwent heart transplantation. 


\section{References}

1. Page, A.R.; Hansen, A.E.; Good, R.A. Occurrence of leukemia and lymphoma in patients with agammaglobulinemia. Blood. 1963;21(2):197-206.

2. Gatti, R.A.; Good, R.A. Occurrence of malignancy in immunodeficiency diseases. Cancer. 1971;28:89-98.

3. Shankaran, V.; Ikeda, H.; Bruce, A.T.; White, J.M.; Swanson, P.E.; Old L.J.; et al. IFN gamma and lymphocytes prevent primary tumour development and shape tumour immunogenicity. Nature. 2001; 410:1107-11.

4. Waldmantn, A.; Strober, W.; Blaeser, M. Immunodeficiency disease and malignancy: various immunologic deficiencies of man and the role of immune processes in the control of malignant disease. Ann Intern Med. 1972;77:605-28.

5. Kersey, J.H.; Spectorb, D.; Good, R.A. Immunodeficiency and cancer. In: Weinhouse S, Klein G, editors. editors. Advances in Cancer Research (Vol. 18), New York: Academic Press; 1973.

6. Sica, A, Vitiello, P, Papa, A, Calogero, A, Sagnelli, C, Casale, D et al. Use of rituximab in NHL malt type pregnant in $\mathrm{I}^{\circ}$ trimester for two times. Open Med (Wars). In press. Open Med (Wars). 2019 Nov 12;14:757-760. doi: 10.1515/med-2019-0087. eCollection 2019.

7. Hoover, R.; Fraumeni, J.F. Risk of cancer in renal-transplant recipients. Lancet. 1973;2:55-7.

8. Calne, R.Y.; White, D.J.; Thiru, S.; Evans, D.B.; McMaster, P.; Dunn, D.C.; et al. Cyclosporin A in patients receiving renal allografts from cadaver donors. Lancet. 1978;2:1323-7.

9. Gasser, S.; Orsulic, S.; Brown, E.J.; Raulet, D.H. The DNA damage pathway regulates innate immune system ligands of the NKG2D receptor. Nature. 2005;436:1186-90. 
10. List, A.F.; Greco, F.A.; Vogler, L.B. Lympho proliferative diseases in immuno-compromised hosts: the role of Epstein-Barr virus. J Clin Oncol. 1987;5:1673-89.

11. Clifford, G.M.; Polesel, J.; Rickenbach, M.; DalMaso, L.; Keiser, O.; Kofler, A.; et al. Cancer risk in the Swiss HIV Cohort Study: associations with immunodeficiency, smoking, and highly active antiretroviral therapy. J Natl Cancer Inst. 2005;97:425-32.

12. Viscardi G, Zanaletti N, Ferrara MG, Sica A, Falcone U, Guastafierro S, Bracale U, Ribero D, Fasano M, Napolitano S, Vitale P, De Falco V, Giunta EF, Martinelli E, Ciardiello D, Ciardiello F, Troiani T. Atypical haemolytic-uraemic syndrome in patient with metastatic colorectal cancer treated with fluorouracil and oxaliplatin: a case report and a review of literature. ESMO Open. 2019;4(5):e000551. doi: 10.1136/esmoopen-2019-000551.

13. Swann, J.B, Smyth, M.J. Immune surveillance of tumors. J Clin Invest. 2007:117:1137-46.

14. Mortaz, E.; Tabarsi, P.; Mansouri, D.; Khosravi, A.; Garssen, J.; Velayati, A.; Adcock, I.M. Cancers Related to Immunodeficiencies: Update and Perspectives. Front Immunol. 2016;7:365.

15. Kaplan, D.H.; Shankaran, V.; Dighe, A.S.; Stockert, E.; Aguet, M.; Old, L.J.;et al. Demonstration of an interferongamma-dependent tumor surveillance system in immunocompetent mice. Proc Natl Acad Sci U S A. 1998;95:7556-61.

16. Jiang, Y.; Villeneuve, P.J.; Wielgosz, A.; et al. The incidence of cancer in a population-based cohort of Canadian heart transplant recipients. Am J Trans. 2010;10:637-645.

17. Na, R.; Grulich, A.E.; Meagher N.S.; et al. Comparison of de novo cancer incidence in Australian liver, heart and lung transplant recipients. Am J Trans. 2013;13:174-183.

18. Sica, A.; Casale, B.; Di Dato, MT.; Calogero, A.; Spada, A.; Sagnelli, C.; et al. Cancer and not cancer related chronic pain: from the physiopathological bases to the management. Open Med (Wars). 2019;14:761-766. DOI: 10.1515/med-2019-0088. 
19. Collett, D.; Mumford, L.; Banner, N.R.; et al. Comparison of the incidence of malignancy in recipients of different types of organ: a UK registry audit. Am J Trans. 2010;10:1889-1896.

20. Girardi, M.; Oppenheim, D.E.; Steele, C.R.; Lewis, J.M.; Glusac, E.; Filler, R.; et al. Regulation of cutaneous malignancy by gamma delta T cells. Science. 2001;294:605-9.

21. Bauer, S.; Groh, V.; Wu, J.; Steinle, A.; Phillips, J.H.; Lanier, L.L.; et al. Activation of NK cells and T cells by NKG2D, a receptor for stress-inducible MICA. Science. 1999;285:727-9.

22. Dunn, G.P.; Bruce, A.T.; Sheehan, K.C.; Shankaran, V.; Uppaluri, R.; Bui, J.D.; et al. A critical function for type I interferons in cancer immunoediting. Nat Immunol. 2005;6:722-9.

23. Street, S.E.; Trapani, J.A.; MacGregor, D.; Smyth, M.J. Suppression of lymphoma and epithelial malignancies effected by interferon gamma. J Exp Med. 2002;196:129-34.

24. Melum, E.; Karlsen, T.H.; Schrumpf, E.; Bergquist, A.; Thorsby, E.; Boberg, K.M.; et al. Cholangiocarcinoma in primary sclerosing cholangitis is associated with NKG2D polymorphisms. Hepatology. 2008;47:90-6.

25. Groh, V.; Rhinehart, R.; Secrist, H.; Bauer, S.; Grabstein, K.H.; Spies, T. Broad tumorassociated expression and recognition by tumor-derived gamma delta T cells of MICA and MICB. Proc Natl Acad Sci U S A. 1999;96:6879-84.

26. Calogero, A.; Sagnelli, C.; Carlomagno, N.; Tammaro, V.; Candida, M.; Vernillo, A.; Peluso, G.; Minieri, G.; Santangelo, M.; Dodaro, C.A.; et al. Familial polyposis coli: The management of desmoid tumor bleeding. Open Med (Wars). 2019;14:572-576. DOI: 10.1515/med-2019-0064. 
27. Vantourout, P.; Willcox, C.; Turner, A.; Swanson, C.M.; Haque, Y.; Sobolev, O.; et al. Immunological visibility: posttranscriptional regulation of human NKG2D ligands by the EGF receptor pathway. Sci Transl Med. 2014;6:231-49.

28. Guerra, N.; Tan, Y.X.; Joncker, N.T.; Choy, A.; Gallardo, F.; Xiong, N.; et al. NKG2Ddeficient mice are defective in tumor surveillance in models of spontaneous malignancy. Immunity. 2008;28:571-80.

29. Lynch, R.C.; Gratzinger, D.; Advani, R.H. Clinical Impact of the 2016 Update to the WHO Lymphoma Classification. Curr Treat Options Oncol. 2017;18(7):45. DOI: 10.1007/s11864-0170483-Z.

30. Merli, M.; Frigeni M.; Alric L.; Visco, C.; Besson, C.; Mannelli, L.; Di Rocco.; A, Ferrari, A.; Farina, L.; Pirisi, M.; Piazza, F.; Loustaud-Ratti, V.; Arcari, A.; Marino, D.; Sica, A.; Goldaniga, M.; Rusconi, C.; Gentile, M.; Cencini, E.; Benanti, F.; Rumi M.G.; Ferretti V.V.; Grossi, P.; Gotti, M.; Sciarra.; R, Tisi, M.C.; Cano, I.; Zuccaro, V.; Passamonti, F.; Arcaini, L. Direct-Acting Antivirals in Hepatitis C Virus-Associated Diffuse Large B-cell Lymphomas. Oncologist. 2019; 24(8):e720-e729. DOI: 10.1634/theoncologist.2018-0331.

31. Chen, D.; Juko-Pecirep, I.; Hammer, J.; Ivansson, E.; Enroth, S.; Gustavsson, I.; et al. Genomewide association study of susceptibility loci for cervical cancer. J Natl Cancer Inst. 2013;105:62433.10.1093/jnci/djt051.

32. Reginelli, A.; Belfiore M.P.; Russo, A.; Turriziani, F. ; Moscarella, E. ; Troiani, T. ; Brancaccio G., Ronchi, A., Giunta, E., Sica A., Iovino, F., Ciardiello, F., Franco, R., Argenziano, G., Grassi R., Cappabianca, S. A preliminary study for quantitative assessment with HFUS (High Frequency ultrasound) of nodular skin melanoma Breslow thickness in adults before surgery: Interdisciplinary team experience. Curr Radiopharm. 2019. DOI: 10.2174/1874471012666191007121626. 
33. Caccavale, S.; Vitiello, P.; Franco, R.; Panarese, I.; Ronchi, A.; Sica, A.; Jurakic, T.R.; Alfano, R.; Argenziano, G. Dermoscopic characterization of folliculotropic mycosis fungoides selectively localized on trunk and limbs. Int J Dermatol. 2019;58(10):e187-e189. DOI: 10.1111/ijd.14490.

34. Sica, A.; Vitiello, P.; Sorriento, A.; Ronchi, A.; Calogero, A.; Sagnelli, C.; Troiani, T.; Fasano, M.; Dodaro C.A.; Franco, R.; Casale, B.; Santangelo, M.; Ciccozzi, M.; Ciardiello, F.; Argenziano, G.; Moscarella, E. Lymphomatoid papulosis. Minerva Medica. In press

35. Minoia, C.; Ciavarella, S.; Lerario, G.; Daniele, A.; De Summa, S.; Napolitano, M.; Guarini, A. Improvable Lifestyle Factors in Lymphoma Survivors. Acta Haematol. 2018;139(4):235-237. DOI: $10.1159 / 000489252$.

36. Martino, M.; Ciavarella, S.; De Summa, S.; Russo, L.; Meliambro, N.; Imbalzano, L.; Gallo, G.A.; Moscato, T.; Messina, G.; Ferreri, A.; Cuzzola, M.; Irrera, G.; Naso, V.; Cimminiello, M.; Console, G.; Loseto, G.; Tommasi, S.; Guarini, A. A Comparative Assessment of Quality of Life in Patients with Multiple Myeloma Undergoing Autologous Stem Cell Transplantation Through an Outpatient and Inpatient Model. Biol Blood Marrow Transplant. 2018;24(3):608-613. DOI: 10.1016/j.bbmt.2017.09.021.

37. Ciavarella, S.; Minoia, C.; Quinto, A.M.; Oliva, S.; Carbonara, S.; Cormio, C.; Cox, M.C.; Bravo, E.; Santoro, F.; Napolitano, M.; Spina, M.; Loseto, G.; Guarini, A. Improving Provision of Care for Long-term Survivors of Lymphoma. Clin Lymphoma Myeloma Leuk. 2017;17(12):e1-e9. DOI: 10.1016/j.clml.2017.08.097.

38. Melton, L.; Brewer, B.; Kolva, E.; Joshi, T.; and Bunch, M. Increasing access to care for young adults with cancer: results of a quality-improvement project using a novel telemedicine approach to supportive group psychotherapy. Palliat Support Care. 2017;15: 176-180. 
39. Fischetti, F.; Greco, G.; Cataldi, S.; Minoia, C.; Loseto, G.; Guarini, A. Effects of Physical Exercise Intervention on Psychological and Physical Fitness in Lymphoma Patients. Medicina (Kaunas). 2019;55(7). pii: E379. DOI: 10.3390/medicina55070379.

40. Courneya, K.S.; Sellar, C.M.; Stevinson, C.; McNeely, M.L.; Peddle, C.J.; Friedenreich C.M.; Tankel, K.; Basi, S.; Chua, N.; Mazurek, A.; et al. Randomized controlled trial of the effects of aerobic exercise on physical functioning and quality of life in lymphoma patients. J. Clin. Oncol. 2009;27:4605-4612. DOI: 10.1200/JCO.2008.20.0634

41. Lucía, A.; Earnest, C.; Pérez M. Cancer-related fatigue: Can exercise physiology assist oncologists? Lancet Oncol. 2003;4:616-625. DOI: 10.1016/S1470-2045(03)01221-X.

42. Global Recommendations on Physical Activity for Health. WHO Library Cataloguing-inPublication Data 2010; (C) World Health Organization. ISBN 9789241599979.

43. Mannocci, A.; Di Thiene, D.; Del Cimmuto, A.; Masala, D.; Boccia, A.; De Vito, E.; La Torre, G. International Physical Activity Questionnaire: validation and assessment in an Italian sample. Ital J Public Health 2010; 7(4):369-76.

44. Coppola, N.; Pisaturo, M.; Guastafierro, S.; Tonziello, G.; Sica, A.; Iodice, V.; et al. Increased hepatitis $\mathrm{C}$ viral load and reactivation of liver disease in HCV RNA-positive patients with oncohaematological disease undergoing chemotherapy. Dig Liver Dis. 2012;44(1):49-54. DOI: 10.1016/j.dld.2011.07.016.

45. Pisaturo, M.; Guastafierro, S.; Filippini, P.; Tonziello, G.; Sica, A.; Di Martino, F.; et al. Absence of occult $\mathrm{HCV}$ infection in patients experiencing an immunodepression condition. Infez Med. 2013;21(4):296-301. 
46. Coppola, N.; Pisaturo, M.; Guastafierro, S.; Tonziello, G.; Sica, A.; Sagnelli, C.; et al. Absence of occult hepatitis $\mathrm{C}$ virus infection in patients under immunosupressive therapy for oncohematological diseases. Hepatology. 2011;54(4):1487-9. DOI: 10.1002/hep.24436.

47. Tonziello, G.; Pisaturo, M.; Sica, A.; Ferrara, M.G.; Sagnelli, C.; Pasquale, G.; et al. Transient reactivation of occult hepatitis $\mathrm{B}$ virus infection despite lamivudine prophylaxis in a patient treated for non-Hodgkin lymphoma. Infection. 2013;41(1):225-9. DOI: 10.1007/s15010-012-0305-y.

48. Sica, A.; Casale, B.; Spada, A.; Di Dato, M.T.; Sagnelli, C.; Calogero, A.; Buonavolontà, P.; Salzano, A.; Martinelli, E.; Saracco, E.; Troiani, T.; Dodaro, C.A.; Tammaro, D.; De Rimini, M.L.; Ciardiello, F.; Papa A. Differential diagnosis: retroperitoneal fibrosis and oncological diseases. Open Med (Wars). In Press. DOI: 10.1515/med-2020-0005.

49. Jäämaa-Holmberg, S.; Salmela, B.; Lemström, K.; Pukkala, E.; Lommi, J. Cancer incidence and mortality after heart transplantation - A population-based national cohort study. Acta Oncol. 2019;58(6):859-863. DOI: 10.1080/0284186X.2019.1580385.

50. Botta, L.; Dal Maso, L.; Guzzinati, S.; Panato, C.; Gatta, G.; Trama, A.; Rugge, M.; Tagliabue, G.; Casella, C.; Caruso B.; Michiara, M.; Ferretti, S.; Sensi, F, Tumino, R.; Toffolutti, F.; Russo, AG.; Caiazzo, A.L.; Mangone, L.; Mazzucco, W.; Iacovacci, S.; Ricci P.; Gola, G.; Candela, G.; Sardo A.S.; De Angelis, R.; Buzzoni, C.; Capocaccia, R; AIRTUM Working Group. Changes in life expectancy for cancer patients over time since diagnosis. J Adv Res. 2019;20:153-159. DOI: 10.1016/j.jare.2019.07.002. 